\title{
Pelo lugar da identidade no pós-contemporâneo
}

\section{Eduardo Mariz'}

Resumo: O ensaio visual Pelo lugar da identidade no pós-contemporâneo sugere uma busca fabular de autocompreensões diante do abrupto isolamento imposto pela chegada da pandemia do Covid-19 no Rio de Janeiro. O grupo de imagens fotográficas, manifestadas em autorretratos, se formaram como espelhamentos a partir de observações nas condutas de vizinhos, jamais relevados em contextos diversos.

Palavras-chaves: Fotografia contemporânea. Performance arte. Pandemia.

\section{For a place of identity in post contemporary}

Abstract: The visual essay For A Place of Identity in Post Contemporary suggests a fabled search for self-understanding in the face of the abrupt isolation imposed by the arrival of the Covid-19 pandemic in Rio de Janeiro. The group of photographic images, manifested in self-portraits, were formed as mirrors from observations in the behavior of neighbors, never revealed in different contexts.

Keywords: Contemporary photography. Performance art. Pandemic.

I Eduardo Mariz é artista, doutor e mestre em artes pela UERJ e pós-graduado em fotografia pela UCAM-RJ. Conclama os conceitos de além do retângulo, o da foto-assemblage e o de acumulonimbus como metodologias práticas artísticas, promovendo a construção e leitura de imagens como ações artístico-performáticas. Trabalha com fotografia, vídeo e performance. Discente da Universidade do Estado do Rio de Janeiro - R. São Francisco Xavier, 524 - Maracanã, Rio de Janeiro - RJ, 20550-013. E-mail: edumariz8@gmail.com. ORCID: https://orcid.org/0000-0002-0990-5020. Lattes iD: http://lattes.cnpq.br/9504060744990245. Rio de Janeiro, RJ, Brasil. 
Figura 2

Eduardo Mariz. Pandemia selfie n_04, 2020.

Fotografia, dimensões variadas

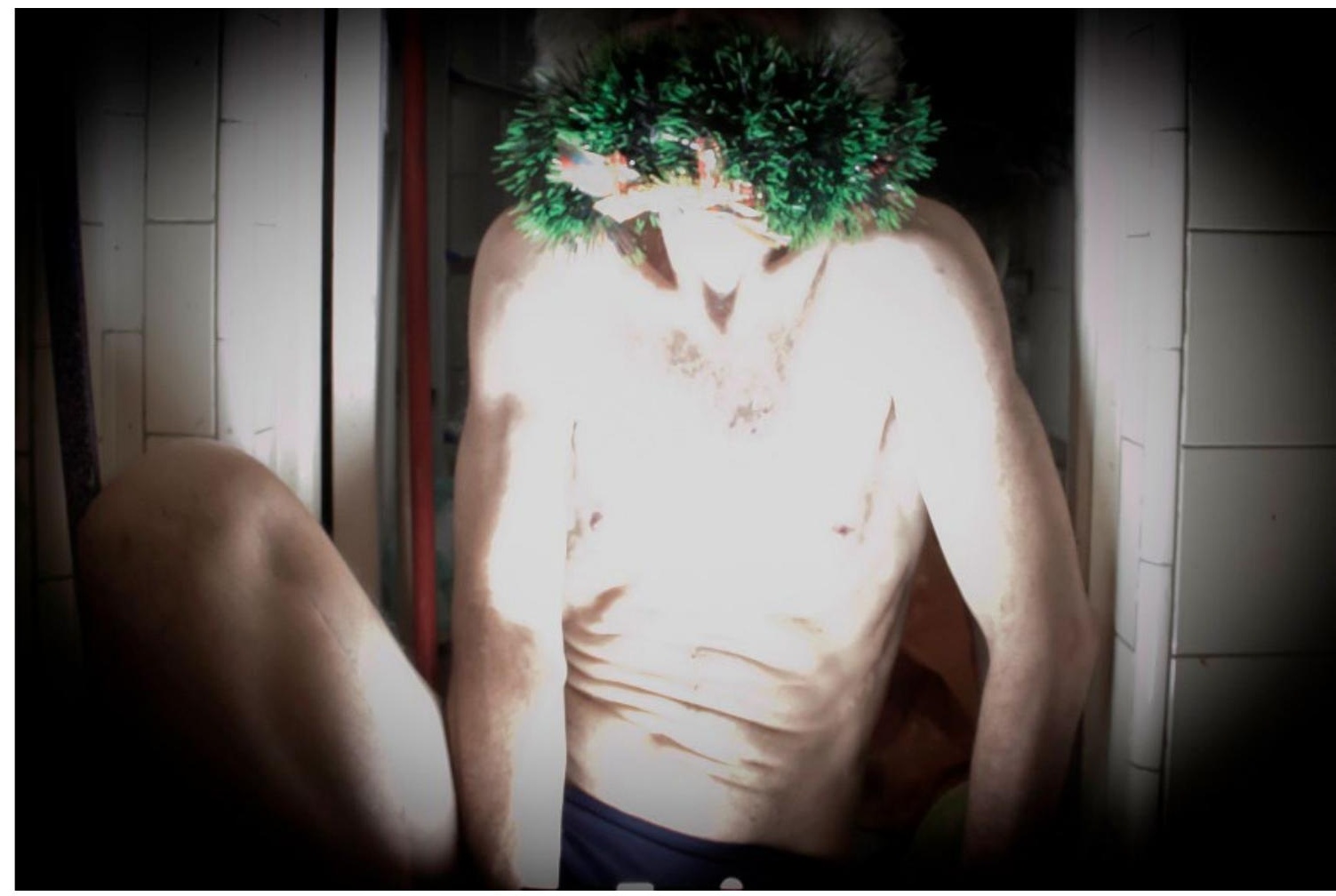

Figura 3

Eduardo Mariz. Pandemia selfie n_03, 2020.

Fotografia, dimensões

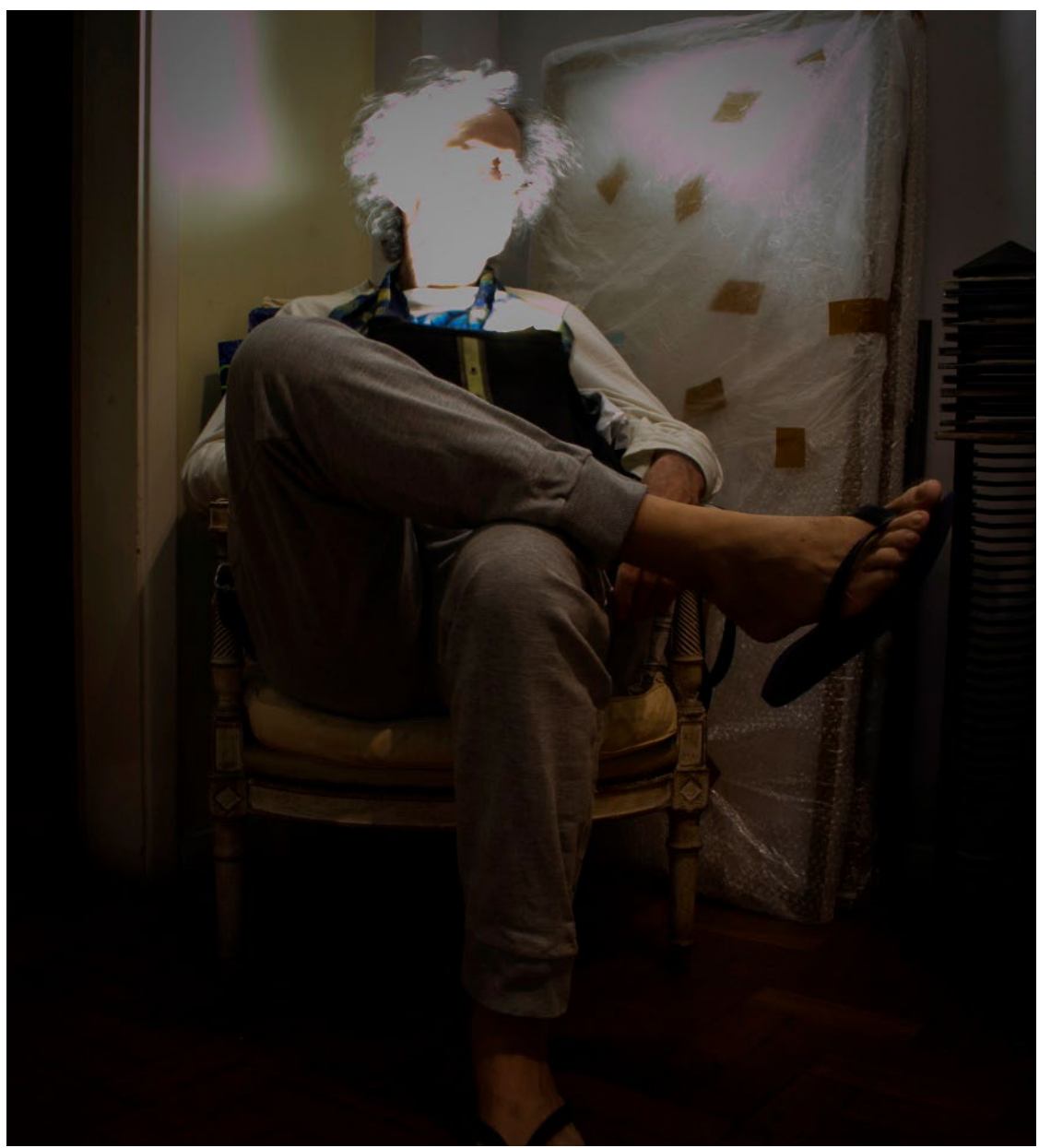

variadas 
$\mathrm{Na}$ afluência das múltiplas identidades, que nos acostumamos a manter pelos pleitos da vida contemporânea, um encontro se processa ao reagrupá-las em limitado ambiente imposto.

No isolamento, rumando talvez para um eixo mais próximo das essências, novos sentidos se mesclam com alguns achados em degraus passados e consolidam bases para a reorganização premente. Ressonâncias daquilo que nos conduziu até aqui.

Entendendo a existência como um devir, na etapa dessa convergência talvez vivamos coisas como a dor esquecida do parto que nos trouxe a esse mundo. Assim, possivelmente, nasceremos para o que está por vir....

Estes autorretratos foram realizados durante o isolamento acarretado pela pandemia, na qual ainda estamos imersos, e conduzem vivências correlatas a tal situação.

Na primeira imagem, que integra também um trabalho em vídeo, procurei versar sobre embates com inimigos não alcançáveis, que envolvem diversos campos com os quais estamos a lidar nesses tempos. Nas duas fotografias seguintes, recortei meu rosto através de um foco de iluminação direta provocando um intenso contraste com o ambiente, sugerindo desfigurações para que, sobre essas, possivelmente, se reconfigurem em novas faces. São máscaras de luz. Na quarta imagem, da série Abyssalis, traço analogia com a ideia de atentar para os costumes dos vizinhos, o que nunca me ocorreu, mas espontaneamente ou forçosamente aconteceu a partir do confinamento. Como o meu apartamento tem disposição em $L$ enxergo de um cômodo uma janela de outro quarto. É possível ver meu próprio ambiente como um vizinho. Assim coloquei minha própria imagem usando acessórios que me descaracterizam de uma autocompreensão. Acionando o timer da câmera, corri para outro quarto, para lá aparecer reorganizado. Cabe avaliações sobre o quanto de nós possuímos naquilo que se assimilamos como produto do meio.

Através dessas imagens procuro filigranar reflexões poéticas sobre possíveis modus vivendi, direcionando-os talvez a presságios sobre uma era que se anuncia. 

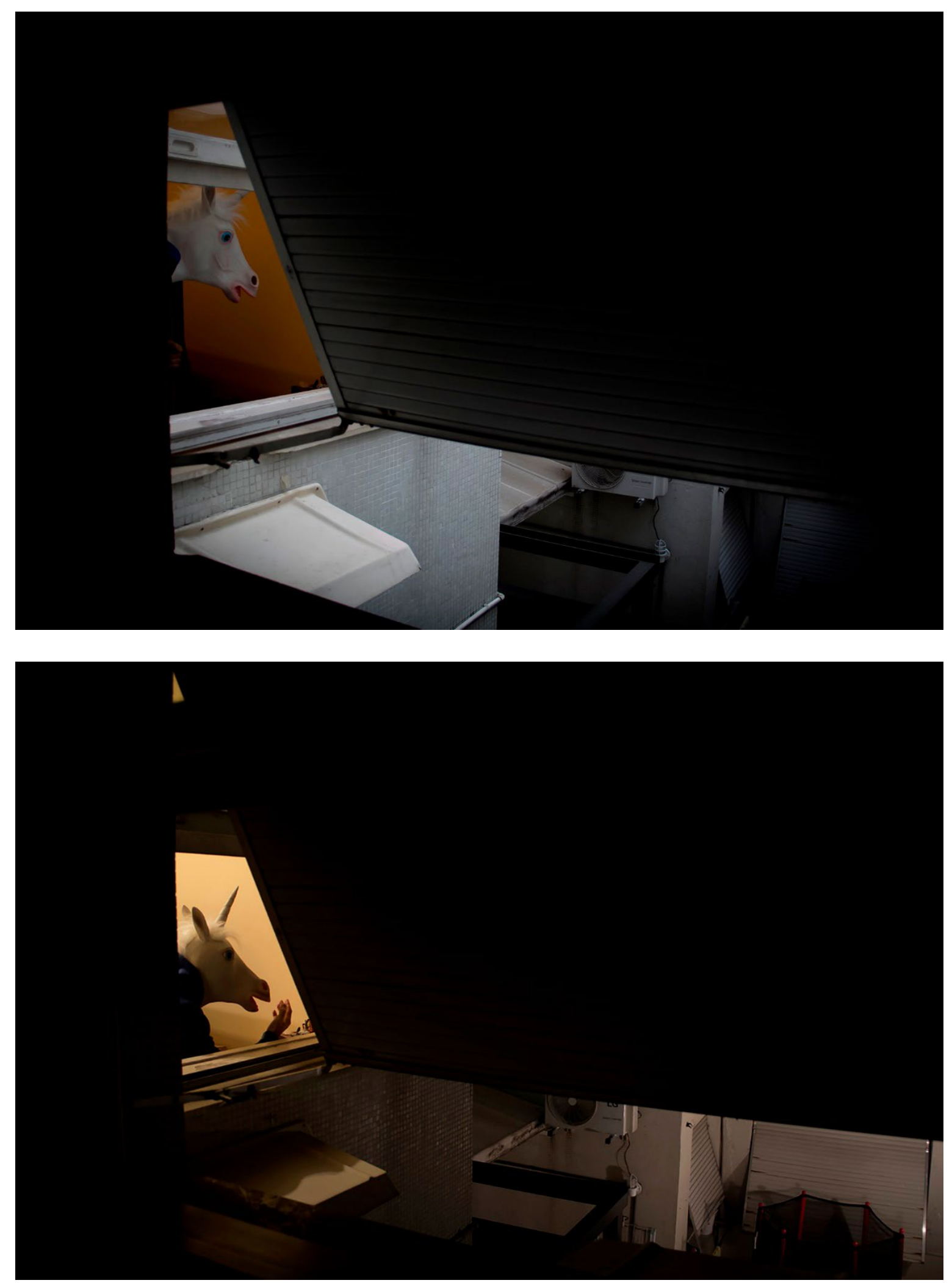

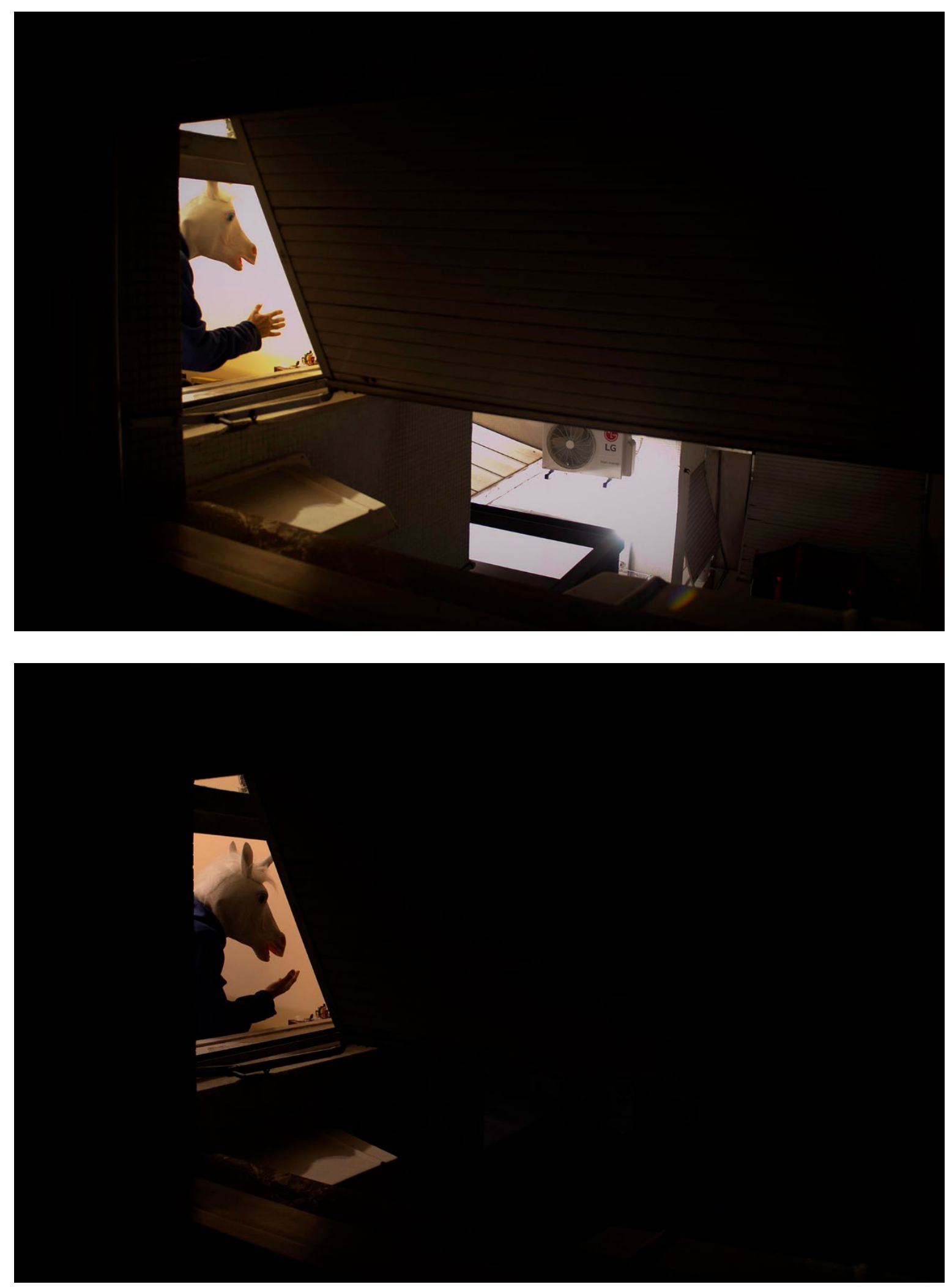
Figura 4

Eduardo Mariz. Abyssalis 01, 2020

Fotografia,

$30 \times 45 \mathrm{~cm}$

Figura 5

Eduardo Mariz.

Abyssalis 02, 2020

Fotografia,

$30 \times 45 \mathrm{~cm}$

Figura 6

Eduardo Mariz.

Abyssalis 03, 2020

Fotografia,

$30 \times 45 \mathrm{~cm}$

Figura 7

Eduardo Mariz.

Abyssalis 04, 2020

Fotografia,

$30 \times 45 \mathrm{~cm}$

\section{Referência}

HALL, Stuart. A Identidade Cultural na Pós-modernidade. $11^{a}$ Edição; tradução Tomaz Tadeu da Silva e Guaracira Lopes Louro. Rio de Janeiro: DP\&A, 2006. 